\title{
Life Style of the College Going Students of Rural and Urban Area in Relation to their Level of Modernization
}

\section{Santosh Kumar Sharma* and Bimla}

Department of Education, Motherhood University, Roorkee, Uttrakhand, India

*Corresponding author: bimlasharma379@gmail.com

Received: 10 Oct., 2020

Revised: 25 Nov., 2020

Accepted: 15 Dec., 2020

\begin{abstract}
This study attempts to compare the life style of the college going students of rural and urban area in relation to their level of modernization. The objective of the study was to find the difference in the different kinds of lifestyle of rural and urban area in relation to their level of modernization. The researcher has used normative survey method in this study. Disproportionate stratified random sampling technique has been used to select 600 students from the degree colleges of rural and urban area of district Haridwar. A significant difference has been found in the health conscious lifestyle, academic oriented lifestyle, career oriented lifestyle, socially oriented lifestyle, trend seeking lifestyle, family oriented lifestyle as well as overall lifestyle of the college going students of rural and urban area. There has been found a significant difference in the health conscious lifestyle, academic oriented lifestyle, career oriented lifestyle, socially oriented lifestyle, trend seeking lifestyle, family oriented lifestyle as well as overall lifestyle of the college going students in relation to modernization.
\end{abstract}

Keywords: Lifestyle, College going Students, Rural and Urban Area, Modernization.

Lifestyles are the choices and options of individuals which put great effect on his mental, social, political and cultural health and wealth. Lifestyle is the way of living in various social contexts and it also affects the social and individual prestige among the community, society and inter-cultural settings. In the above context Oygard \& Andersen (1998) has indicated that lifestyle available to an individual is a function 
of education, relationships, socialization, personality, physical and mental ability, situational factors and goals, financial and other material resources. Lifestyle predicts the physical, mental, emotional and social status of an individual. There are many incidences which show the advantages of good lifestyle as well as negative consequences of unhealthy lifestyle. Stock, Mikolajczyk, Bilir, Petkeviciene, Naydenova, Dudziak, Marin- Fernandez, \& Ansari (2007) indicated that unhealthy lifestyles account for a high number of mortalities. Adaramaja, Adenubi, \& Alabi (2010) found that high blood pressure, arthritis, weight gain, stress and diabetes can be prevented by a healthy lifestyle. It is observed that the students of the present time are leading unhealthy lifestyle, which is an issue of major concern. It negatively affects the various aspects of the life of the students. Forrest, Bevans, Riley, Crespo, \& Louis (2013) stated that unhealthy lifestyle of the students leads them to poor academic achievement.

Change is the law of nature and human being is also part of this change. Mechanization of the every walk of life has brought modernization in the life of human being. Technological advancement has made it possible for everyone to access everything at any time. It has drastically changed the lifestyle of the individuals. Now the preferences and choices for the academics, career, family and socially are taking sharp turns. At this juncture of time it becomes imperative to study and compare the life style of the college going students of rural and urban area in relation to their level of modernization. This study will help the college going students who are exposed to the modern world to adapt a healthy lifestyle.

\section{Objectives of the Study}

The objective of the present study is to compare the life style of the college going students of rural and urban area in relation to their level of modernization.

\section{Hypotheses of the Study}

Following null hypotheses have been formed in the present study:

1. There is no significant difference in the health conscious lifestyle of the college going students of rural and urban area in relation to modernization.

2. There is no significant difference in the academic oriented lifestyle of the college going students of rural and urban area in relation to modernization.

3. There is no significant difference in the career oriented lifestyle of the college going students of rural and urban area in relation to modernization.

4. There is no significant difference in the socially oriented lifestyle of the college going students of rural and urban area in relation to modernization.

5. There is no significant difference in the trend seeking lifestyle of the college going students of rural and urban area in relation to modernization. 
6. There is no significant difference in the family oriented lifestyle of the college going students of rural and urban area in relation to modernization.

7. There is no significant difference in the lifestyle of the college going students of rural and urban area in relation to modernization.

\section{Methodology}

Method of the Study: The researcher has used normative survey method in this study.

Sample and Sampling Technique: In the present study, disproportionate stratified random sampling technique has been used to select 600 college going students from the degree colleges of rural and urban area of district Haridwar. The sample comprised of 300 rural and 300 urban students.

Variables: Lifestyle is the dependent variable of the present study whereas modernization is the independent variable of the present study.

Research Scale Used: Life Style Scale developed by S.K. Bawa and Sumanpreet Kaur and Modernization Scale developed by Raghavendra S. Singh, Amar Nath Tripathi and Ramjee Lal has been used to collect the data.

Statistical Techniques: Mean, S.D. and two-way analysis of variance have been used for the statistical analysis.

\section{Analysis and Interpretation of Data}

Table 1: Health Conscious Lifestyle of the College going Students of Rural and Urban Area in relation to Modernization

\begin{tabular}{llllll}
\hline \multirow{2}{*}{ Variable } & \multirow{2}{*}{ Area } & Levels of Modernization & \multirow{2}{*}{ N } & \multicolumn{2}{c}{ Health Conscious Lifestyle } \\
\cline { 5 - 6 } & & & Mean & S.D. \\
\hline \multirow{3}{*}{ Rural } & Highly Modernized & 07 & 20.00 & 2.58 \\
Health Conscious & & Average Modernized & 291 & 20.59 & 3.81 \\
Lifestyle in relation to & & Conservative & 02 & 16.00 & 0.00 \\
Modernization & \multirow{3}{*}{ Urban } & Highly Modernized & 31 & 21.87 & 5.18 \\
& & Average Modernized & 221 & 21.95 & 4.58 \\
& & Conservative & 48 & 27.95 & 8.16 \\
\hline
\end{tabular}

The table 1 shows that the college going students of rural area who are highly modernized and average modernized adapt average health conscious lifestyle while students of rural area who are conservative adapt below average health conscious lifestyle. Similarly, college going students of urban area who are highly modernized and average modernized adapt average health conscious lifestyle while the students of urban area who are conservative adapt above average health conscious lifestyle. 
Table 2: Analysis of Variance

\begin{tabular}{llllll}
\hline Source & df & SS & MS & F-value & Results \\
\hline Area & 1 & 316.959 & 316.959 & $14.679^{* *}$ & Significant \\
Modernization & 2 & 1287.814 & 643.907 & $29.820^{* *}$ & Significant \\
Interaction & 2 & 212.732 & 106.366 & $4.926^{* *}$ & Significant \\
Between Group & 6 & 285610.629 & 47601.772 & & \\
Within Group & 594 & 12826.371 & 21.593 & & \\
\hline
\end{tabular}

** = Significant at 0.01 level.

The table 2 shows that at df 1 and 594, the first obtained F-value is 14.679, which has been found significant at 0.01 level of significance. It shows a significant difference in the health conscious lifestyle of the college going students of rural and urban area.

At df 2 and 594, the second obtained F-value is 29.820, which has also been found significant at 0.01 level of significance. It indicates that there is a significant difference in the health conscious lifestyle of the college going students in relation to modernization.

At df 2 and 594, the third obtained F-value is 4.926, which has been found significant at 0.01 level of significance. It suggests that interaction of area and modernization has created a significant effect on the health conscious lifestyle of the college going students.

It may be concluded that all F-values are found significant. Thus, the sub-hypothesis that "there is no significant difference in the health conscious lifestyle of the college going students of rural and urban area in relation to modernization" is altogether rejected.

Table 3: Academic Oriented Lifestyle of the College going Students of Rural and Urban Area in relation to Modernization

\begin{tabular}{llllll}
\hline \multirow{2}{*}{ Variable } & \multirow{2}{*}{ Area } & Levels of Modernization & \multirow{2}{*}{$\mathbf{N}$} & \multicolumn{2}{c}{ Academic Oriented Lifestyle } \\
\cline { 4 - 5 } & & & & Mean & S.D. \\
\hline \multirow{3}{*}{$\begin{array}{l}\text { Academic Oriented } \\
\text { Lifestyle in relation to }\end{array}$} & & Highly Modernized & 07 & 19.42 & 2.69 \\
Modernization & Average Modernized & 291 & 18.62 & 2.47 \\
& \multirow{2}{*}{ Urban } & Conservative & 02 & 18.00 & 0.00 \\
& & Highly Modernized & 31 & 19.96 & 4.85 \\
& & Average Modernized & 221 & 19.49 & 3.72 \\
& Conservative & 48 & 25.41 & 4.17 \\
\hline
\end{tabular}

The table 3 shows that the college going students of rural area who are highly modernized, average modernized and conservative adapt average academic oriented lifestyle. On the other hand, college going students of urban area who are highly modernized and average modernized adapt average academic oriented lifestyle while the students of urban area who are conservative adapt above average academic oriented lifestyle. 
Life Style of the College Going Students of Rural and Urban Area in Relation...

Table 4: Analysis of Variance

\begin{tabular}{llllll}
\hline Source & df & SS & MS & F-value & Results \\
\hline Area & 1 & 120.839 & 120.839 & $11.198^{* *}$ & Significant \\
Modernization & 2 & 1314.326 & 657.163 & $60.900^{* *}$ & Significant \\
Interaction & 2 & 82.011 & 41.006 & $3.800^{*}$ & Significant \\
Between Group & 6 & 231624.231 & 38604.038 & & \\
Within Group & 594 & 6409.769 & 10.791 & & \\
\hline
\end{tabular}

** = Significant at 0.01 level; * = Significant at 0.05 level.

The table 4 shows that at df 1 and 594, the first obtained F-value is 11.198, which has been found significant at 0.01 level of significance. It shows that there is a significant difference in the academic oriented lifestyle of the college going students of rural and urban area.

At df 2 and 594, the second obtained F-value is 60.900, which has also been found significant at 0.01 level of significance. It shows a significant difference in the academic oriented lifestyle of the college going students in relation to modernization.

At df 2 and 594, the third obtained F-value is 3.800, which has been found significant at 0.05 level of significance. It suggests that joint effect of area and modernization has created a significant effect on the academic oriented lifestyle of the college going students.

It may be concluded that all F-values are found significant. Thus, the sub-hypothesis that "there is no significant difference in the academic oriented lifestyle of the college going students of rural and urban area in relation to modernization" is altogether rejected.

Table 5: Career Oriented Lifestyle of the College going Students of Rural and Urban Area in relation to Modernization

\begin{tabular}{llllll}
\hline \multirow{2}{*}{ Variable } & \multirow{2}{*}{ Area } & Levels of Modernization & \multirow{2}{*}{} & \multicolumn{2}{c}{ Career Oriented Lifestyle } \\
\cline { 5 - 6 } & & & Mean & S.D. \\
\hline \multirow{3}{*}{ Rural } & Highly Modernized & 07 & 19.14 & 1.95 \\
Career Oriented & & Average Modernized & 291 & 18.88 & 3.52 \\
Lifestyle in relation to & & Conservative & 02 & 14.00 & 0.00 \\
Modernization & \multirow{2}{*}{ Urban } & Highly Modernized & 31 & 22.58 & 3.64 \\
& & Average Modernized & 221 & 20.13 & 3.84 \\
& & Conservative & 48 & 22.12 & 4.94 \\
\hline
\end{tabular}

The table 5 shows that the college going students of rural area who are highly modernized and average modernized adapt average career oriented lifestyle while students of rural area who are conservative adapt below average career oriented lifestyle. On the other hand, college going students of urban area who are highly modernized, average modernized and conservative adapt average career oriented lifestyle. 
Table 6: Analysis of Variance

\begin{tabular}{llllll}
\hline Source & df & SS & MS & F-value & Results \\
\hline Area & 1 & 277.064 & 277.064 & $19.544^{* *}$ & Significant \\
Modernization & 2 & 212.296 & 106.148 & $7.488^{* *}$ & Significant \\
Interaction & 2 & 113.170 & 56.585 & $3.991^{*}$ & Significant \\
Between Group & 6 & 235665.159 & 39277.527 & & \\
Within Group & 594 & 8420.841 & 14.176 & & \\
\hline
\end{tabular}

$* *=$ Significant at 0.01 level; $*=$ Significant at 0.05 level.

The table 6 shows that at df 1 and 594, the first obtained F-value is 19.544, which has been found significant at 0.01 level of significance. It shows a significant difference in the career oriented lifestyle of the college going students of rural and urban area.

At df 2 and 594, the second obtained F-value is 7.488, which has also been found significant at 0.01 level of significance. It indicates that there is a significant difference in the career oriented lifestyle of the college going students in relation to modernization.

At df 2 and 594, the third obtained F-value is 3.991, which has been found significant at 0.05 level of significance. It means that combined effect of area and modernization has created a significant effect on the career oriented lifestyle of the college going students.

It may be concluded that all F-values are found significant. Thus, the sub-hypothesis that "there is no significant difference in the career oriented lifestyle of the college going students of rural and urban area in relation to modernization" is altogether rejected.

Table 7: Socially Oriented Lifestyle of the College going Students of Rural and Urban Area in relation to Modernization

\begin{tabular}{llllll}
\hline \multirow{2}{*}{ Variable } & \multirow{2}{*}{ Area } & Levels of Modernization & \multirow{2}{*}{ N } & \multicolumn{2}{c}{ Socially Oriented Lifestyle } \\
\cline { 5 - 6 } & & & & Mean & S.D. \\
\hline \multirow{3}{*}{$\begin{array}{l}\text { Socially Oriented } \\
\text { Lifestyle in relation to }\end{array}$} & \multirow{3}{*}{ Rural } & Highly Modernized & 07 & 19.71 & 3.86 \\
Modernization & & Average Modernized & 291 & 17.01 & 3.04 \\
& \multirow{3}{*}{ Urban } & Conservative & 02 & 11.50 & 2.12 \\
& & Highly Modernized & 31 & 19.87 & 4.01 \\
& & Average Modernized & 221 & 18.64 & 3.44 \\
& & Conservative & 48 & 23.66 & 3.68 \\
\hline
\end{tabular}

The table 7 shows that the college going students of rural area who are highly modernized and average modernized adapt average socially oriented lifestyle while students of rural area who are conservative adapt below average socially oriented lifestyle. On the other hand, college going students of urban area who are highly modernized and average modernized adapt average socially oriented lifestyle while the students of urban area who are conservative adapt above average socially oriented lifestyle. 
Table 8: Analysis of Variance

\begin{tabular}{llllll}
\hline Source & df & SS & MS & F-value & Results \\
\hline Area & 1 & 393.518 & 393.518 & $35.898^{* *}$ & Significant \\
Modernization & 2 & 883.698 & 441.849 & $40.307^{* *}$ & Significant \\
Interaction & 2 & 224.511 & 112.256 & $10.240^{* *}$ & Significant \\
Between Group & 6 & 203224.536 & 33870.756 & & \\
Within Group & 594 & 6511.464 & 10.962 & & \\
\hline
\end{tabular}

** = Significant at 0.01 level.

The table 8 shows that at df 1 and 594, the first obtained F-value is 35.898, which has been found significant at 0.01 level of significance. It means that there is a significant difference in the socially oriented lifestyle of the college going students of rural and urban area.

At df 2 and 594, the second obtained F-value is 40.307, which has also been found significant at 0.01 level of significance. It shows that there is a significant difference in the socially oriented lifestyle of the college going students in relation to modernization.

At df 2 and 594, the third obtained F-value is 10.240, which has been found significant at 0.01 level of significance. It shows that interaction of area and modernization has created a significant effect on the socially oriented lifestyle of the college going students.

It may be concluded that all F-values are found significant. Thus, the sub-hypothesis that "there is no significant difference in the socially oriented lifestyle of the college going students of rural and urban area in relation to modernization" is altogether rejected.

Table 9: Trend Seeking Lifestyle of the College going Students of Rural and Urban Area in relation to Modernization

\begin{tabular}{|c|c|c|c|c|c|}
\hline \multirow{2}{*}{ Variable } & \multirow{2}{*}{ Area } & \multirow{2}{*}{ Levels of Modernization } & \multirow{2}{*}{$\mathbf{N}$} & \multicolumn{2}{|c|}{ Trend Seeking Lifestyle } \\
\hline & & & & Mean & S.D. \\
\hline \multirow{6}{*}{$\begin{array}{l}\text { Trend Seeking } \\
\text { Lifestyle in relation to } \\
\text { Modernization }\end{array}$} & \multirow{3}{*}{ Rural } & Highly Modernized & 07 & 21.71 & 2.69 \\
\hline & & Average Modernized & 291 & 23.62 & 2.93 \\
\hline & & Conservative & 02 & 24.00 & 0.00 \\
\hline & \multirow{3}{*}{ Urban } & Highly Modernized & 31 & 22.70 & 4.89 \\
\hline & & Average Modernized & 221 & 24.84 & 4.45 \\
\hline & & Conservative & 48 & 28.83 & 7.34 \\
\hline
\end{tabular}

The table 9 shows that the college going students of rural area who are highly modernized and average modernized adapt below average trend seeking lifestyle while students of rural area who are conservative adapt average trend seeking lifestyle. On the other hand, college going students of urban area who are highly modernized adapt below average trend seeking lifestyle while the students of urban area who are average modernized and conservative adapt average trend seeking lifestyle. 
Table 10: Analysis of Variance

\begin{tabular}{llllll}
\hline Source & df & SS & MS & F-value & Results \\
\hline Area & 1 & 212.234 & 212.234 & $12.408^{* *}$ & Significant \\
Modernization & 2 & 853.322 & 426.661 & $24.944^{* *}$ & Significant \\
Interaction & 2 & 25.120 & 12.560 & 0.734 & Insignificant \\
Between Group & 6 & 359103.641 & 59850.607 & & \\
Within Group & 594 & 10160.359 & 17.105 & & \\
\hline
\end{tabular}

** = Significant at 0.01 level.

The table 10 shows that at df 1 and 594, the first obtained F-value is 12.408, which has been found significant at 0.01 level of significance. It reveals a significant difference in the trend seeking lifestyle of the college going students of rural and urban area.

At df 2 and 594, the second obtained F-value is 24.944, which has also been found significant at 0.01 level of significance. It shows that there is a significant difference in the trend seeking lifestyle of the college going students in relation to modernization.

At df 2 and 594, the third obtained F-value is 0.734, which has not been found significant even at 0.05 level of significance. It suggests that interaction of area and modernization has not created a significant effect on the trend seeking lifestyle of the college going students.

It may be concluded that two F-values are found significant while one F-value is found insignificant. Thus, the sub-hypothesis that "there is no significant difference in the trend seeking lifestyle of the college going students of rural and urban area in relation to modernization" is mostly rejected and partly accepted.

Table 11: Family Oriented Lifestyle of the College going Students of Rural and Urban Area in relation to Modernization

\begin{tabular}{llllll}
\hline \multirow{2}{*}{ Variable } & \multirow{2}{*}{ Area } & Levels of Modernization & \multirow{2}{*}{ N } & \multicolumn{2}{c}{ Family Oriented Lifestyle } \\
\cline { 5 - 6 } & & & & Mean & S.D. \\
\hline \multirow{3}{*}{ Family Oriented } & \multirow{3}{*}{ Rural } & Highly Modernized & 07 & 24.42 & 2.22 \\
Lifestyle in relation to & & Average Modernized & 291 & 24.40 & 2.44 \\
Modernization & & Conservative & 02 & 23.00 & 2.82 \\
& \multirow{3}{*}{ Urban } & Highly Modernized & 31 & 30.41 & 6.80 \\
& & Average Modernized & 221 & 26.04 & 4.40 \\
& & Conservative & 48 & 30.72 & 5.88 \\
\hline
\end{tabular}

The table 11 shows that the college going students of rural area who are highly modernized, average modernized and conservative adapt low family oriented lifestyle. On the other hand, college going students of urban area who are average modernized adapt below average family oriented lifestyle while the students of urban area who are highly modernized and conservative adapt average family oriented lifestyle. 
Table 12: Analysis of Variance

\begin{tabular}{llllll}
\hline Source & df & SS & MS & F-value & Results \\
\hline Area & 1 & 488.619 & 488.619 & $32.023^{* *}$ & Significant \\
Modernization & 2 & 1045.510 & 522.755 & $34.260^{* *}$ & Significant \\
Interaction & 2 & 169.209 & 84.605 & $5.545^{* *}$ & Significant \\
Between Group & 6 & 402591.469 & 67098.578 & & \\
Within Group & 594 & 9063.531 & 15.258 & & \\
\hline
\end{tabular}

** = Significant at 0.01 level.

The table 12 shows that at df 1 and 594, the first obtained F-value is 32.023, which has been found significant at 0.01 level of significance. It means that there is a significant difference in the family oriented lifestyle of the college going students of rural and urban area.

At df 2 and 594, the second obtained F-value is 34.260, which has also been found significant at 0.01 level of significance. It shows a significant difference in the family oriented lifestyle of the college going students in relation to modernization.

At df 2 and 594, the third obtained F-value is 5.545, which has been found significant at 0.01 level of significance. It means that joint effect of area and modernization has created a significant effect on the family oriented lifestyle of the college going students.

It may be concluded that all F-values are found significant. Thus, the sub-hypothesis that "there is no significant difference in the family oriented lifestyle of the college going students of rural and urban area in relation to modernization" is altogether rejected.

Table 13: Lifestyle of the College going Students of Rural and Urban Area in relation to Modernization

\begin{tabular}{llllll}
\hline \multirow{2}{*}{ Variable } & \multirow{2}{*}{ Area } & Levels of Modernization & N & \multicolumn{2}{c}{ Lifestyle } \\
\cline { 5 - 6 } & & Highly Modernized & 07 & 124.42 & 7.65 \\
& \multirow{3}{*}{ Rural } & Average Modernized & 291 & 123.15 & 12.59 \\
Lifestyle in relation to & & Conservative & 02 & 106.50 & 0.70 \\
Modernization & \multirow{3}{*}{ Urban } & Highly Modernized & 31 & 137.41 & 15.93 \\
& & Average Modernized & 221 & 131.13 & 18.30 \\
& & Conservative & 48 & 158.72 & 15.89 \\
\hline
\end{tabular}

The table 13 shows that the college going students of rural area who are highly modernized and average modernized adapt below average lifestyle while students of rural area who are conservative adapt poor lifestyle. On the other hand, college going students of urban area who are highly modernized adapt average lifestyle while college going students of urban area who are average modernized adapt below average lifestyle. But the students of urban area who are conservative adapt above average lifestyle. 
Table 14: Analysis of Variance

\begin{tabular}{llllll}
\hline Source & df & SS & MS & F-value & Results \\
\hline Area & 1 & 10394.117 & 10394.117 & $44.236^{* *}$ & Significant \\
Modernization & 2 & 26845.239 & 13422.620 & $57.125^{* *}$ & Significant \\
Interaction & 2 & 3805.904 & 1902.952 & $8.099^{* *}$ & Significant \\
Between Group & 6 & 10139378.217 & 1689896.369 & & \\
Within Group & 594 & 139571.783 & 234.969 & & \\
\hline
\end{tabular}

** = Significant at 0.01 level.

The table 14 shows that at df 1 and 594, the first obtained F-value is 44.236, which has been found significant at 0.01 level of significance. It indicates that there is a significant difference in the lifestyle of the college going students of rural and urban area.

At df 2 and 594, the second obtained F-value is 57.125, which has also been found significant at 0.01 level of significance. It shows a significant difference in the lifestyle of the college going students in relation to modernization.

At df 2 and 594, the third obtained F-value is 8.099, which has been found significant at 0.01 level of significance. It reveals that combined effect of area and modernization has created a significant effect on the lifestyle of the college going students.

It may be concluded that all F-values are found significant. Thus, the sub-hypothesis that "there is no significant difference in the lifestyle of the college going students of rural and urban area in relation to modernization" is altogether rejected.

\section{Findings of the Study}

The findings of the present study are as follows:

A significant difference has been found in the health conscious lifestyle, academic oriented lifestyle, career oriented lifestyle, socially oriented lifestyle, trend seeking lifestyle, family oriented lifestyle as well as overall lifestyle of the college going students of rural and urban area. College going students of urban area were found to adapt better health conscious lifestyle, academic oriented lifestyle, career oriented lifestyle, socially oriented lifestyle, trend seeking lifestyle, family oriented lifestyle as well as overall lifestyle as compared to college going students of rural area.

There has been found a significant difference in the health conscious lifestyle, academic oriented lifestyle, career oriented lifestyle, socially oriented lifestyle, trend seeking lifestyle, family oriented lifestyle as well as overall lifestyle of the college going students in relation to modernization. 
Interaction of area and modernization has been found to create a significant effect on the health conscious lifestyle, academic oriented lifestyle, career oriented lifestyle, socially oriented lifestyle, family oriented lifestyle as well as overall lifestyle of the college going students. College going students of urban area who were conservative were found to adapt best health conscious lifestyle, academic oriented lifestyle, socially oriented lifestyle, family oriented lifestyle as well as overall lifestyle. College going students of urban area who were highly modernized were found to adapt best career oriented lifestyle.

Interaction of area and modernization has not been found to create a significant effect on the trend seeking lifestyle of the college going students.

\section{REFERENCES}

1. Adaramaja, S.R., Adenubi, O.S. and Alabi, Y.L. 2010. Influence of demographic factors on the lifestyles of tertiary institutions students in Kwara State, Nigeria: Educational media and counseling interventions. Research Journal of Applied Sciences, 5(2): 73-77.

2. $\quad$ Forrest, C.B., Bevans, K.B., Riley, A.W., Crespo, R. and Louis, T.A. 2013. Health and school outcomes during children's' transition into adolescence. Journal of Adolescent Health, 52(2): 186-194.

3. Oygard, L. and Andersen, N. 1998. Social influences and leisure-time physical activity in young people: A twelve year follow-up study. Journal of Health Psychology, 3(1): 59-69.

4. Stock, C., Mikolajczyk, R.T., Bilir, N., Petkeviciene, J., Naydenova, V., Dudziak, U., Marin- Fernandez, B. and Ansari, W. 2007. Gender differences in students' health complaints: A survey in seven countries. Journal of Public Health, 16(5): 353-360. 
